\title{
The epidemiology of multiple sclerosis in the entre Douro e Vouga region of northern Portugal: a multisource population-based study
}

Mariana Branco ${ }^{1,2}$, Ivânia Alves ${ }^{3}$, Ana Martins da Silva ${ }^{4,5}$, Joaquim Pinheiro ${ }^{6}$, Maria José Sá ${ }^{7,8}$, Inês Correia ${ }^{9}$, Lívia Sousa ${ }^{9}$, Eva Brandão ${ }^{1}$, Carlos Veira ${ }^{1}$, Bernardo Gomes ${ }^{10}$ and Luis Ruano ${ }^{1,2,11^{*}}$ (D)

Abstract: Background: The prevalence of Multiple Sclerosis (MS) has been increasing worldwide and the northsouth gradient of prevalence may be disappearing in the Northern hemisphere. The few previous prevalence studies performed in Portugal have reported a lower prevalence than the average for Western Europe. The aim of this study is to estimate the prevalence of MS in the Entre Douro e Vouga region, in Northern Portugal.

Methods: Multiple overlapping sources were used to ascertain all cases from the reference population: records from hospitals in the region and neighbouring regions; diagnostic databases of primary care physicians; and applications for disability benefits. The prevalence date was set at 1 January 2014. The reference population was 274,859 inhabitants. Patients' neurologists were contacted to retrieve clinical information and confirm the diagnosis based.

Results: A total of 177 patients were identified after eliminating duplicates from different sources. The female to male ratio was 1.9 and the mean age at disease onset was 33.5 (standard deviation: 10.3). Clinically isolated syndrome accounted for $9.0 \%$ of patients, relapsing remitting for $58.8 \%$, secondary progressive for $20.3 \%$ and primary progressive for $11.8 \%$. The prevalence was estimated in 64.4 patients per 100,000 (95\% confidence interval: 54.9;73.9).

Conclusions: In this study we report a higher point prevalence of MS than had been previously described in Portugal, but still far from the higher values recently reported in other Southern European countries.

Keywords: Multiple sclerosis, Epidemiology, Prevalence, Portugal

\footnotetext{
* Correspondence: Imruano@gmail.com

${ }^{1}$ Serviço de Neurologia, Centro Hospitalar de Entre Douro e Vouga, Santa Maria da Feira, Portugal

²Departamento de Ciências da Saúde Pública e Forenses e Educação Médica,

Faculdade de Medicina, Universidade do Porto, Porto, Portugal

Full list of author information is available at the end of the article
}

(c) The Author(s). 2020 Open Access This article is licensed under a Creative Commons Attribution 4.0 International License, which permits use, sharing, adaptation, distribution and reproduction in any medium or format, as long as you give appropriate credit to the original author(s) and the source, provide a link to the Creative Commons licence, and indicate if changes were made. The images or other third party material in this article are included in the article's Creative Commons licence, unless indicated otherwise in a credit line to the material. If material is not included in the article's Creative Commons licence and your intended use is not permitted by statutory regulation or exceeds the permitted use, you will need to obtain permission directly from the copyright holder. To view a copy of this licence, visit http://creativecommons.org/licenses/by/4.0/. The Creative Commons Public Domain Dedication waiver (http://creativecommons.org/publicdomain/zero/1.0/) applies to the data made available in this article, unless otherwise stated in a credit line to the data. 


\section{Background}

Multiple sclerosis (MS) is a chronic inflammatory disease of the central nervous system. The early onset and the progressive disabling course of the disease cause a major impact on patients' life and represent a relevant social and economic burden in western societies [1,2].

The uneven distribution of MS across the globe has puzzled epidemiologists and neurologists for almost a century. A latitudinal gradient of the prevalence of MS has long been described $[3,4]$. However, a systematic review of prevalence studies suggested that this prevalence gradient could be disappearing in Northern America and Western Europe, while it persists in Australia and New Zealand [5]. Although these findings were not confirmed in a second systematic review [6], more recent studies from Southern Europe have reported prevalence values similar to the ones usually described in Northern European countries [7-10].

Epidemiological data regarding MS in Portugal are scarce. A population-based study performed in 1998 in the region of Santarem, in central Portugal, reported a prevalence of 46.3 per 100,000 [11]. Another population based performed in 2009 identified a crude prevalence of 41.4 per 100,000 in three primary-care districts from Lisbon [12]. A third prevalence study, also performed in 2009 , yielded a prevalence of 39.8 per 100,000 in the district of Braga, but relied only in hospital records for case identification [13]. Currently, there is no published population-based epidemiological data on the female to male ratio, age of onset, and the distribution of the different clinical courses of MS in Portugal.

This study aims to describe the epidemiology and prevalence of MS in the region of Entre Douro-e-Vouga in Northern Portugal, using a multisource populationbased approach.

\section{Methods}

\section{Study design and setting}

This is a multi-source population-based study on the prevalence and epidemiology of MS in Entre Douro e Vouga region. The study was approved by the ethics committee of the Regional Health Authority for Northern Portugal, that also gave permission to waive individual informed consent for data access, with all the patient data de-identified prior to data collection.

The Entre Douro e Vouga region is a well-defined geographical region located in Northern Portugal, classified as a Level III region in the European Nomenclature of Territorial Units for Statistics. The Entre Douro e Vouga region spans over urban, suburban and rural areas and has an area of $861 \mathrm{~km}^{2}$ and a population of 274.859 , including the counties of Arouca, São João da Madeira, Santa Maria da Feira, Vale de Cambra, and Oliveira de Azemeis. Within this region, there are 26 primary care units, where 159 General Practitioners (GPs) work. The coverage and usage of the Portuguese National Health Service (NHS) is extensive in the Portuguese population. GPs refer patients with neurological disorders to a single reference hospital for neurological disorders within the NHS. However, this hospital was created 20 years ago, and previously diagnosed patients with MS could be followed in hospitals from larger cities in the nearby regions. There are no private hospitals with neurology departments in the region. The immunomodulatory drugs used in the treatment of MS are restricted to hospital use in Portugal and are fully refundable through the NHS; therefore, they are hardly ever used outside NHS hospitals.

\section{Patient ascertainment methods}

Patient ascertainment was performed from three potentially overlapping sources: 1) Hospital records, 2) Primary care diagnostic databases and 3) Applications for disability benefits. In the next paragraphs, we detail how patient search was performed in each of the sources.

(1) Hospital records: Patient search was performed in the only referring hospital for neurological disorders in the region and in hospitals from nearby regions with a Neurology department. In each hospital, the records of the neurology outpatient clinics were reviewed to identify all patients with MS living in the Entre Douro e Vouga region.

(2) Primary care diagnostic databases: The coding system used to classify patients in primary care settings in Portugal is the electronic version of the International Classification of Primary Care, second edition [14]. The electronic databases of all primary care units within the Entre Douro e Vouga region were searched for the code N86 (multiple sclerosis).

(3) Applications for disability benefits: To receive tax benefits or exemption of co-payments patients with MS must apply for a medical evaluation in the Public Health Unit of the area of residence. The application records for medical evaluations in the Entre Douro e Vouga public health department from October 2009 to July 2014 were reviewed to identify applicants with possible MS.

The period of patient ascertainment was from January to July 2014. To identify and discard duplicates, the NHS number, the current address and date of birth were retrieved for each patient, using an algorithm to anonymize and match identical records.

\section{Inclusion criteria}

For all the unique records identified through the different sources, the patient's neurologist was contacted and 
asked to provide clinical information and confirm a diagnosis of MS on the 1st of January 2014, based on the 2017 McDonald criteria [15]. The patients were confirmed to be alive at the prevalence date trough analysis of recent visits to primary and hospital care and death certificates.

\section{Clinical data collection}

Patients' neurologists were asked to review the patients clinical records and provide additional data: sex, age of onset, disease duration, physical disability according to the Expanded Disability Status Scale (EDSS) [16] and current clinical form of the disease: 1) clinically isolated syndrome (CIS) 2) relapsing remitting (RR) 3) secondary progressive (SP) or 4) primary progressive (PP) according to the 2013 revision of the Lublin criteria [17].

\section{Data analysis}

The mean age, age of onset and median EDSS were calculated for the whole sample and each disease course. Prevalence is reported as the number of patients per 100,000. It was age-standardized using the direct method. Data from the last census, in 2011 were used to estimate the population of the Entre Douro e Vouga region and to define the Portuguese reference population $[18,19]$. For the European population, the European Standard Population 2013 [20] was used. An estimate of the overall prevalence, corrected using the capture-recapture method was also calculated, using the maximum likelihood estimator methodology [21]. Retrospectively estimated incidence rates were calculated for the three-year periods of 2005-2007, 2008-2010 and 2011-2013. The statistical analysis was performed using SPSS 24.0.

\section{Results}

A total of 174 patients where identified from hospital records. All the 5 public hospitals that have Neurology departments located in the nearby regions collaborated in the study. Patients living in the Entre Douro e Vouga region were identified in 4 of these 5 hospitals. A total of 172 records were retrieved from the primary care diagnostic databases, 145 of them confirmed to have MS, the others corresponding to coding errors. Regarding applications for disability benefits, 61 patients were identified, all with confirmed MS by their Neurologist and previously identified by hospital records (Fig. 1).

A total of 177 unique patients were identified after eliminating duplicates, yielding a crude prevalence estimate of 64.4 patients per 100,000 with a $95 \%$ confidence interval (CI) of 54.9 to 73.9 per 100,000 . The agestandardized prevalence for the Portuguese population was 61.8 per 100,000 and for the European standard population 60.0 per 100,000 .

The retrospectively estimated incidence rate from 2005 to 2007 was 2.5 (95\% CI: 1.6; 3.9), from 2008 to 2010 it was 2.7 (95\% CI: 1.7:4.0) and from 2011 to 2013 it was 3.1 new patients per 100,000 person-years $(95 \%$ CI: 2.1;4.6).

For the capture-recapture analysis, we used the two sources that provided unique cases 1 ) hospital records and 2) primary care diagnostic databases, as the third source (applications for disability benefits) was not suitable for this method, as it did not yield cases not independently identified from hospital records (Fig. 1). The probability of case identification by hospital records was 0.98; the probability of identification from primary care diagnostic databases was 0.80 . The expected number of overlapping cases was 139.1, similar to the observed number (142). The number of total estimated patients

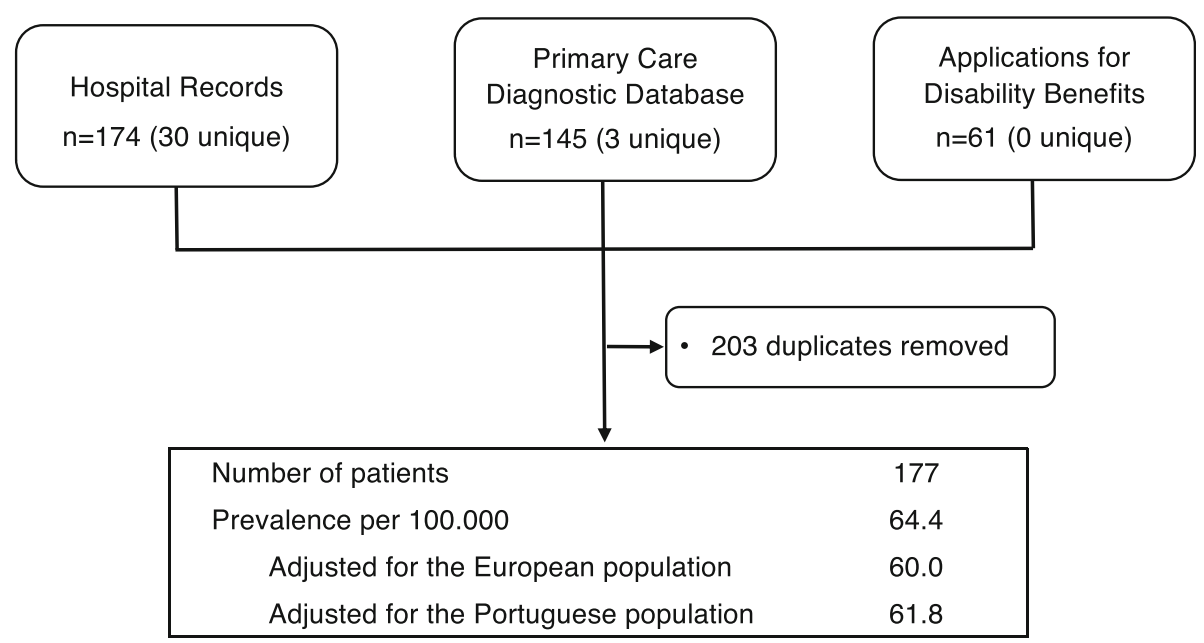

Fig. 1 Flow chart and prevalence data 
Table 1 Clinical and demographic characteristics of the study patients

\begin{tabular}{llllll}
\hline & $\mathrm{CIS}(n=16)$ & $\mathrm{RR}(n=104)$ & $\mathrm{SP}(n=36)$ & $\mathrm{PP}(n=21)$ & Total sample $(n=177)$ \\
\hline Age, mean (SD), years & $35.5(7.6)$ & $41.9(11.7)$ & $54.2(10.3)$ & $54.2(10.2)$ & $44.5(11.9)$ \\
Sex ratio (female/male) & 2.0 & 1.9 & 1.4 & 1.2 & 1.9 \\
Age at onset, mean (SD), years & $32.4(6.0)$ & $31.4(10.0)$ & $35.0(10.7)$ & $42.9(9.2)$ & $33.5(10.3)$ \\
Disease duration, mean (SD), years & $4.5(3.9)$ & $10.8(6.8)$ & $16.7(9.5)$ & $11.7(7.1)$ & $11.5(7.9)$ \\
EDSS, median (IQR) & $1.0[0.0 ; 2.0]$ & $2.0[1.0 ; 3.0]$ & $5.0[4.0 ; 6.5]$ & $6.5[5.5 ; 7.5]$ & $2.0[1.0 ; 6.0]$
\end{tabular}

CIS clinically isolated syndrome; $R R$ relapsing remitting; SP secondary progressive; $P P$ primary progressive; SD standard deviation; $I Q R$ interquartile range EDSS expanded disability status scale

was 181.4 and the prevalence adjusted by this method was 66.0 patients per 100,000 .

The patients' mean age was 44.5 (standard deviation (SD): 11.9) and the median EDSS was 2.0 (interquartile range: $1.0 ; 6.0$ ). CIS course accounted for $9.0 \%$ of patients, RR course for $58.8 \%$ of patients, SP for $20.3 \%$ and PP for $11.9 \%$. The mean age at onset was 33.5 (SD: 10.3), 32.4 in patients with CIS, 31.4 in RR, 35.0 in SP and 42.9 in PP. The female to male ratio was 1.9 overall, 2.0 in patients with CIS, 1.9 in RR, 1.4 in SP and 1.2 in PP (Table 1).

\section{Discussion}

In this multi-source population-based study we estimated a prevalence of MS of 64.4 patients per 100,000, higher than previously described in Portugal (Table 2), but still far from the highest values recently reported in other southern European countries [22].

The previous prevalence studies in Portugal, performed a decade or more ago, reported figures ranging from 39.8 to 46.3 patients per 100,000 [11-13]. However, we must be cautious when comparing these results. The inclusion of patients in some of the previous studies relied on older diagnostic criteria, excluding patients with CIS. Nevertheless, even when removing these patients from our current estimate, the point prevalence is still higher, at 58.6 patients per 100,000 (CI: 50.0; 68.0). However, the confidence interval overlaps with the Santarem study, with 46.3 patients per 100,000 (CI: 29.563.2). Additionally, the higher prevalence in this study could reflect a better case finding when compared with previous studies, due to the use of multiple sources and records from hospitals in nearby regions.

While the study was not designed with this goal, we performed a post-hoc analysis of the data to estimate incidence trends. There was a trend to an increase in incidence, but with no statistical significance. The estimated incidence is lower than generally described in Europe, in line with the prevalence figs [23]..

The multisource design of this study and the extensive cooperation of MS centres from contiguous regions gives us confidence that we were able to identify most of the affected patients in the region. Nevertheless, older and more disabled patients, particularly those with progressive courses of disease, are less prone to have a regular follow up at hospital clinics when compared with younger, less disabled patients with CIS or RR course. While we tried to identify those patients using primary health care databases and applications for disability benefits, there were probably missed cases resulting in an overall underestimation of the prevalence of the disease. The relatively low median EDSS of the overall sample (2.0), when compared to what is generally reported for prevalent cases [24-26], is possibly a reflection of a lower ascertainment rate of older and more disabled patients in the present studies. Nevertheless, we identified a larger number of patients with primary progressive course (SP 20.3\%; PP 11.9\%) when compared with previous Portuguese studies (Santarem: SP 20.1\% and PP 3.4\%; Braga: SP $14.2 \%$ and PP 2.0\%). Concerning the Braga study, the lower prevalence of progressive course is in agreement to a lower mean age in that sample, 35.4 vs. 44.5 in the present study. The Santarem study sample

Table 2 Studies on the prevalence of multiple sclerosis in Portugal

\begin{tabular}{|c|c|c|c|c|c|c|}
\hline Author & Year & Design & Pop. & Area & N & Prevalence per 100,000 [95\% Cl] \\
\hline De Sá, J [11]. & 1999 & Multisource population-based & 62,621 & Santarem District & 29 & $\begin{array}{l}46.3 \\
{[29.5-63.2]}\end{array}$ \\
\hline De Sá, J [12]. & 2009 & Multisource population-based & 229,342 & Lisbon (three parishes) & 95 & $\begin{array}{l}41.4 \\
{[33.5-50.6]}\end{array}$ \\
\hline Figueiredo J [13]. & 2009 & Hospital based & 866,012 & Braga district & 345 & $\begin{array}{l}39.8 \\
{[27.5-52.2]}\end{array}$ \\
\hline Branco, M (present study) & 2014 & Multisource population-based & 274,859 & Entre Douro e Vouga Region & 177 & $\begin{array}{l}64.4 \\
{[54.9-73.9]}\end{array}$ \\
\hline
\end{tabular}


had a similar mean age, but its small dimension (29 patients) limits the comparisons. Early preliminary data from an ongoing project to build a national MS registry from an initial pool of 561 patients from several MS centres identified $8.6 \%$ of patients as PP and $10.4 \%$ as SP [27].

We performed a capture-recapture analysis of the prevalence data using previously described methodology [21]. However, we must interpret this result caution, given as the assumption of source independence Indeed, it is expected that patients that have a regular follow-up at the MS clinic (first source) are more likely to attend and have a correct diagnosis registered at a Primary Care (second source). Indeed, only two sources that provided unique cases 1) hospital records and 2) primary care diagnostic databases, as the third source (applications for disability benefits) did not yield any cases that were not independently identified from hospital records. This is similar to the unadjusted prevalence, due to the completeness of the hospital sources, that identified 174 of the 177 unique patients.

On the assumption that the prevalence in the Entre Douro e Vouga region is higher than in other regions of Portugal, we can speculate on some hypotheses. Recent research strongly suggests that organic solvents could play a role in the development of MS [28], and these compounds are widely used in footwear manufacturing [29]. This region has an important footwear industry [30] and shoe factories are remarkable local employers, which makes us hypothesize that there is a higher number of people exposed to organic solvents than in other regions of the country and this may eventually contribute to a higher prevalence of MS. Additional studies considering the professional activities of patients are needed to clarify this issue.

While recent studies in southern Europe have reported prevalence values similar to the ones usually described in northern European countries [7-10], the prevalence reported in this study, and indeed in previous Portuguese studies, is still lower than the European average [22]. Some factors may help to explain this lower prevalence. Vitamin D is a well-known protective factor against the development of MS [31]. Portugal is a small country with an extensive coastline, and the large majority of the population is concentrated in the cost, having easy access to bathing areas. In larger countries like Spain and Italy there is a higher proportion of the population that lives far from the coast and, and probably a lower average number of annual hours of sunbathing. The Portuguese population has a higher prevalence of sunburns compared to other southern countries, namely Italy and Greece, supporting the hypothesis of a more intense sun exposure [32]. Nevertheless, there is still an important vitamin D deficiency in the Portuguese population [33], and particularly in patients with MS [34]. Ethnic and racial distribution could also play a role in these results. African populations have a low prevalence of MS [35] and Portugal is historically one of the main destination countries for African migrants in Southern Europe [36].

The female to male ratio was 1.9, lower than what has been reported in Northern European countries [5], where this ratio has been increasing, reflecting an increasingly higher relative incidence in females [37, 38]. One potential explanation for this increase is the loss of the relatively long-lasting protective factor of pregnancy since there is a trend to lower birth rates. However, this trend is even more pronounced in Portugal than in Northern European countries [39]. There are currently no other factors able to justify the gender differences in the epidemiology of MS [40], therefore we can only suppose that genetic or environmental factors might play a role on this difference, with Portuguese women having a more protective profile than their northern counterparts, or Portuguese men being more susceptible.

\section{Conclusions}

In conclusion, we report the highest point prevalence of MS in a study performed in Portugal. This could be due to regional variance, differences in study methodology and inclusion criteria, a higher number of diagnosis due to an increased awareness of physicians about the disease, or environmental and genetic factors. Further studies are needed to truly understand the trends in the epidemiology of MS in Portugal.

\section{Abbreviations}

MS: Multiple sclerosis; Cl: Confidence interval; GPs: General Practitioners; NHS: Portuguese National Health Service; EDSS: Expanded Disability Status Scale; CIS: Clinically isolated syndrome; RR: Relapsing remitting; SP: Secondary progressive; PP: Primary progressive

\section{Acknowledgements}

Not applicable.

\section{Availability of data and material}

The datasets used and/or analysed during the current study are available from the corresponding author on reasonable request.

\section{Conflict of interest}

The authors declare no conflicting interests.

\section{Authors' contributions}

MB collected, analysed and interpreted data and was the main contributor in writing the manuscript. LR and BG designed the study, collected patient data and provided and contributed to writing and reviewing the manuscript. IA, AMS, JP, LS, MJS, LV, IC, EB and CV collected patient data and contributed to writing and reviewing the manuscript. All authors read and approved the final manuscript.

Funding

There was no funding for this project. 


\section{Ethics approval and consent to participate}

The study was approved by the ethics committee of the Regional Health Authority for Northern Portugal, that also gave permission to waive individual informed consent for data access, with all the patient data deidentified prior to data collection.

\section{Consent for publication}

Not applicable.

\section{Competing interests}

The authors declare that they have no competing interests.

\section{Author details}

${ }^{1}$ Serviço de Neurologia, Centro Hospitalar de Entre Douro e Vouga, Santa Maria da Feira, Portugal. ${ }^{2}$ Departamento de Ciências da Saúde Pública e Forenses e Educação Médica, Faculdade de Medicina, Universidade do Porto, Porto, Portugal. ${ }^{3}$ Serviço de Neurologia, Centro Hospitalar do Tâmega e Sousa, Penafiel, Portugal. ${ }^{4}$ Serviço de Neurologia Hospital de Santo António, Centro Hospitalar Universitário do Porto, Porto, Portugal. ${ }^{5}$ Unidade Multidisciplinar de Investigação Biomédica (UMIB), Instituto Ciências Biomédicas Abel Salazar, Universidade do Porto, Porto, Portugal. ${ }^{6}$ Serviço de Neurologia, Centro Hospitalar de Vila Nova de Gaia/Espinho, Vila Nova de Gaia, Portugal. ${ }^{7}$ Serviço de Neurologia, Centro Hospitalar de São João, Porto, Portugal. ${ }^{8}$ Faculdade de Ciências da Saúde, Universidade Fernando Pessoa, Porto, Portugal. ${ }^{9}$ Serviço de Neurologia, Centro Hospitalar e Universitário de Coimbra, Coimbra, Portugal. ${ }^{10}$ Unidade de Saúde Pública, ACES Entre Douro e Vouga I, Santa Maria da Feira, Portugal. ${ }^{11}$ EPIUnit - Instituto de Saúde Pública, Universidade do Porto, Porto, Portugal.

Received: 9 June 2019 Accepted: 30 April 2020

Published online: 19 May 2020

\section{References}

1. Collaborators GBDMS. Global, regional, and national burden of multiple sclerosis 1990-2016: a systematic analysis for the Global Burden of Disease Study 2016. Lancet Neurol. 2019;18(3):269-85.

2. Sá MJ, Kobelt G, Berg J, Capsa D, Dalén J. New insights into the burden and costs of multiple sclerosis in Europe: Results for Portugal. Mult Scler J. 2017; 23(2_suppl):143-54.

3. Davenport CB. Multiple sclerosis: from the standpcint of geographic distribution and race. Arch Neurol Psychiatr. 1922;8(1):51-8.

4. Grimaldi LM, Palmeri B, Salemi G, Giglia G, D'Amelio M, Grimaldi R, Vitello G, Ragonese P, Savettieri G. High prevalence and fast rising incidence of multiple sclerosis in Caltanissetta, Sicily, southern Italy. Neuroepidemiology. 2007:28(1):28-32.

5. Koch-Henriksen N, Sorensen PS. The changing demographic pattern of multiple sclerosis epidemiology. Lancet Neurol. 2010;9(5):520-32.

6. Simpson S Jr, Blizzard L, Otahal P, Van der Mei I, Taylor B. Latitude is significantly associated with the prevalence of multiple sclerosis: a metaanalysis. J Neurol Neurosurg Psychiatry. 2011;82(10):1132-41.

7. Granieri E, Monaldini C, De Gennaro R, Guttmann S, Volpini M, Stumpo M, Fazio P, Casetta I. Multiple sclerosis in the Republic of San Marino: a prevalence and incidence study. Mult Scler. 2008;14(3):325-9.

8. Papathanasopoulos P, Gourzoulidou E, Messinis L, Georgiou V, Leotsinidis M. Prevalence and incidence of multiple sclerosis in western Greece: a 23-year survey. Neuroepidemiology. 2008;30(3):167-73.

9. Izquierdo G, Venegas A, Sanabria C, Navarro G. Long-term epidemiology of multiple sclerosis in the northern Seville District. Acta Neurol Scand. 2015: 132(2):111-7.

10. Fernandez O, Fernandez V, Guerrero M, Leon A, Lopez-Madrona JC, Alonso A, Bustamante R, Tamayo JA, Romero F, Bravo M, et al. Multiple sclerosis prevalence in Malaga, southern Spain estimated by the capture-recapture method. Mult Scler. 2012;18(3):372-6.

11. De Sa J, Paulos A, Mendes H, Becho J, Marques J, Roxo J. The prevalence of multiple sclerosis in the district of Santarem, Portugal. J Neurol. 2006;253(7): 914-8.

12. de Sa J, Alcalde-Cabero E, Almazan-Isla J, Sempere A, de Pedro-Cuesta J. Capture-recapture as a potentially useful procedure for assessing prevalence of multiple sclerosis: methodologic exercise using Portuguese data. Neuroepidemiology. 2012;38(4):209-16.
13. Figueiredo J, Silva Â, Cerqueira JJ, Fonseca J, Pereira PA. MS Prevalence and Patients' Characteristics in the District of Braga, Portugal. Neurol Res Int. 2015;2015:4

14. Okkes I, Jamoulle M, Lamberts $\mathrm{H}$, Bentzen N. ICPC-2-E: the electronic version of ICPC-2. Differences from the printed version and the consequences. Fam Pract. 2000;17(2):101-7.

15. Thompson AJ, Banwell BL, Barkhof F, Carroll WM, Coetzee T, Comi G, Correale J, Fazekas F, Filippi M, Freedman MS, et al. Diagnosis of multiple sclerosis: 2017 revisions of the McDonald criteria. Lancet Neurol. 2018;17(2):162-73.

16. Kurtzke JF. Rating neurologic impairment in multiple sclerosis: an expanded disability status scale (EDSS). Neurology. 1983;33(11):1444-52.

17. Lublin FD, Reingold SC, Cohen JA, Cutter GR, Sorensen PS, Thompson AJ, Wolinsky JS, Balcer LJ, Banwell B, Barkhof F, et al. Defining the clinical course of multiple sclerosis: the 2013 revisions. Neurology. 2014;83(3):278-86.

18. População residente do sexo feminino segundo os Censos: total e por grupo etário. Censos 2011 Resultados Definitivos Portugal. Instituto Nacional de Estatistica. Lisboa. 2012

19. População residente do sexo masculino segundo os Censos: total e por grupo etário. Censos 2011 Resultados Definitivos Portugal. Instituto Nacional de Estatistica. Lisboa. 2012

20. European Standard Population 2013 by sex. Eurostat. European Union. 2013.

21. Hook EB, Regal RR. Capture-recapture methods in epidemiology: methods and limitations. Epidemiol Rev. 1995:17(2):243-64.

22. Koutsouraki E, Costa $V$, Baloyannis $\mathrm{S}$. Epidemiology of multiple sclerosis in Europe: a review. Int Rev Psychiatry. 2010;22(1):2-13.

23. Pugliatti M, Rosati G, Carton H, Riise T, Drulovic J, Vécsei L, Milanov I. The epidemiology of multiple sclerosis in Europe. Eur J Neurol. 2006;13(7):700-22.

24. Manouchehrinia A, Beiki O, Hillert J. Clinical course of multiple sclerosis: a nationwide cohort study. Mult Scler. 2017;23(11):1488-95.

25. Ruano L, Portaccio E, Goretti B, Niccolai C, Severo M, Patti F, Cilia S, Gallo P, Grossi $P$, Ghezzi A, et al. Age and disability drive cognitive impairment in multiple sclerosis across disease subtypes. Mult Scler. 2017;23(9):1258-67.

26. Alla S, Pearson JF, Taylor BV, Miller DH, Clarke G, Richardson A, Willoughby E, Abernethy DA, Sabel CE, Mason DF. Disability profile of multiple sclerosis in New Zealand. J Clin Neurosci. 2016;28:97-101.

27. JDF JT, Sequeira J, Grilo M, Samoes R, Varanda S, Morgado J, Guimaraes J, Nunes C, Cerqueira JJFCA, Santos JMV, Sá MJ, Silva AADM, Sousa LMAFD, Pedrosa RMG, de Sa J, Alegria P. Demography, clinical characteristics and socioeconomic status of the Portuguese patients with Multiple Sclerosis in 2014 - results of the national cross-sectional PORT-MS study. In. Eur J Neurol. 2015;22(Suppl.1)

28. Hedstrom AK, Hossjer O, Katsoulis M, Kockum I, Olsson T, Alfredsson L. Organic solvents and MS susceptibility: interaction with MS risk HLA genes. Neurology. 2018;91(5):e455-62

29. Cottica D, Grignani E. Berri a: [exposure to leather dusts and organic solvents-results of the PPTP-shoe study]. G Ital Med Lav Ergon. 2012;34(1):43-5.

30. Becattini G, Bellandi M, De Propris L. A handbook of industrial districts. 1st ed. Cheltenham: Edwars Elgar Publishing Limited; 2009.

31. Munger $\mathrm{KL}$, Ascherio A. Prevention and treatment of MS: studying the effects of vitamin D. Mult Scler. 2011;17(12):1405-11.

32. van der Leest RJ, de Vries E, Bulliard JL, Paoli J, Peris K, Stratigos AJ, Trakatelli M, Maselis TJ, Situm M, Pallouras AC, et al. The Euromelanoma skin cancer prevention campaign in Europe: characteristics and results of 2009 and 2010. J Eur Acad Dermatol Venereol. 2011;25(12):1455-65.

33. Bettencourt A, Boleixa D, Reis J, Oliveira JC, Mendonca D, Costa PP, Silva BMD, Marinho A, Silva AMD. Serum 25-hydroxyvitamin D levels in a healthy population from the north of Portugal. J Steroid Biochem Mol Biol. 2018; 175:97-101.

34. Bettencourt A, Boleixa D, Reguengo H, Samoes R, Santos E, Oliveira JC, Silva B, Costa PP, da Silva AM. Serum 25-hydroxyvitamin D levels in multiple sclerosis patients from the north of Portugal. J Steroid Biochem Mol Biol. 2018;180:137-41.

35. Browne P, Chandraratna D, Angood C, Tremlett H, Baker C, Taylor BV, Thompson AJ. Atlas of multiple sclerosis 2013: a growing global problem with widespread inequity. Neurology. 2014;83(11):1022-4

36. Harding S, Teyhan A, Rosato M, Santana P. All cause and cardiovascular mortality in African migrants living in Portugal: evidence of large social inequalities. Eur J Cardiovasc Prev Rehabil. 2008:15(6):670-6.

37. Westerlind H, Bostrom I, Stawiarz L, Landtblom AM, Almqvist C, Hillert J. New data identify an increasing sex ratio of multiple sclerosis in Sweden. Mult Scler. 2014;20(12):1578-83. 
38. Kampman MT, Aarseth JH, Grytten N, Benjaminsen E, Celius EG, Dahl OP, Holmoy T, Loken-Amsrud K, Midgard R, Myhr KM, et al. Sex ratio of multiple sclerosis in persons born from 1930 to 1979 and its relation to latitude in Norway. J Neurol. 2013;260(6):1481-8.

39. PORDATA: Taxa Bruta de Natalidade segundo o Censos. 2017.

40. Magyari M. Gender differences in multiple sclerosis epidemiology and treatment response. Dan Med J. 2016;63(3):B5212.

\section{Publisher's Note}

Springer Nature remains neutral with regard to jurisdictional claims in published maps and institutional affiliations.

Ready to submit your research? Choose BMC and benefit from:

- fast, convenient online submission

- thorough peer review by experienced researchers in your field

- rapid publication on acceptance

- support for research data, including large and complex data types

- gold Open Access which fosters wider collaboration and increased citations

- maximum visibility for your research: over $100 \mathrm{M}$ website views per year

At $\mathrm{BMC}$, research is always in progress.

Learn more biomedcentral.com/submissions 